\title{
Government Websites of Kerala: An Evaluation using Government of India Guidelines
}

\author{
Rajani S. \\ Department of Computer Science and Applications \\ Bangalore University \\ Bangalore-560056
}

\author{
Muralidhara B.L. \\ Department of Computer Science and Applications \\ Bangalore University \\ Bangalore-560056
}

\begin{abstract}
Government Departments are increasingly using websites as a tool to reach out to the citizens. Through Government websites, the Government can improve the standard of information and ensure maximum reach of government information and services to citizens through different government services published on the web. The objective of Government web services is to reach to all sections of society with respect of distance and language. An organization's official website provides a powerful way to reach out to its potential clients. This paper proposes to evaluate the websites belonging to Government departments in the state of Kerala against guidelines for the same provided by the Government of India. These Guidelines address the entire life cycle of a website, web portal and benefits and can be useful when determining if a website provides trustworthy, up-to-date information and data about how the government operates. The following five criteria are used to determine the quality of information and also for the evaluation of web resources. Accuracy, Authority, Objectivity, Currency, and Coverage are the five factors are elaborated in the Government of India guidelines. The state of Kerala has been selected for this analysis. As per the 2011 census of India, Kerala is the first literate state in India. Kerala was declared a, 'Fully Literate State', on April 18th, 1991. For the purpose of evaluation of government websites, the following four categories of twenty Government departments are considered: Secretariat departments, Directorate/Commissionerates, Government Institutions, and Local Self-Governance.
\end{abstract}

\section{General Terms}

Guidelines, websites, Kerala, Government

\section{Keywords}

Government of India Guidelines, e-Governance

\section{INTRODUCTION}

Electronic Governance or e-Governance essentially refers to 'providing online services to citizens at their door step'. The technology and the methods used in e-Governance project give a roadmap for efficient delivery of services to citizens [1]. The Government of India had planned to use Information Technology (IT), Information and Communication Technologies (ICTs), and other web-based telecommunication technologies to improve the efficiency and effectiveness of service delivery in the public sector [2]. The tremendous growth in ICT has flagged a way for countries around the world to provide e-government services to their citizens [3]. The primary delivery models of e-Governance can be divided into four levels or stages of development services: 1.Government-to-Government (G2G), 2. Government-toCitizen (G2C), 3.Government-to Business (G2B), 4. Citizento-Government $(\mathrm{C} 2 \mathrm{G})$. An informed society is an empowered society. Only informed people can make a Government responsible. So providing access to every piece of information of the Government and of public importance is one of the basic objective of e-Governance [4].

There have been many works to analyze the websites of Government organizations using various parameters. Over 1667 Government websites in 198 nations were evaluated using 18 factors that focus on the amount of information available and the extent of interaction with users [5]. The republic of India has 28 states and 7 union territories with a population is 1.21 billion people [6]. All state Governments in India have established web portals which are increasingly becoming the common communication interface between the citizens and the elected representatives of the respective state.

Kerala is one of the federal states of India. For the purpose of evaluating websites of the Government of Kerala, Government of India guidelines are used [7]. These guidelines have been developed by National Informatics Centre (NIC) and adopted by Department of Administrative reforms and Public Grievances (DARPG) [8]. These guidelines are used for development and management of Government websites and portals in India. The primary objective of these guidelines is to make sure that Indian Government websites, belonging to any constituent of the Government, at any level, are citizen centric and visitor friendly. Guidelines are to ensure a high degree of consistency and uniformity in the content coverage and presentation and further promote excellence in Indian Government web space. Guidelines addresses the following needs in various parameters such as the needs of visitors, including the general public, specialised audiences, people with disabilities, those without access to advanced technologies, and those with limited communication in English[7].

As per the 2011 provisional population figures, the total population of the state of Kerala is 33 million of which male and female are 16 and 17 million respectively. The sex ratio of Kerala is 1084 females per 1000 males. Whereas, the sex ratio of rural areas in Kerala is 1077 and that of urban areas is 1091. The literate population in Kerala is 28 million and total literacy rate is $93.91 \%$. Literacy rate in the rural areas is $92.92 \%$ and that of urban areas is $94.99 \%$ [9]. During 20012011, the state has added only 1.5 million people to its population. The state also tops the chart in maintaining the highest literacy rate of $94 \%$ among other states in India. Kerala is the only state in the country which has the lowest positive population growth rate in India and its sex ratio is considered to be the best of all Indian states [10]. The official language of Kerala is Malayalam.

In the analysis, a total of twenty Government departments were considered [11]. Table 1 shows the list of departments names and their websites. For the evaluation of Kerala Government departments total 103 parameters of Government of India Guidelines are considered. Table 2, describe the groups and parameters used for this examination. The 
Government of India specifies guidelines for Government of India Identifiers (GII), Building Confidence (BC), and Scope of Content: Primary Content (SCp), Secondary Content (SCs) and Tertiary Content (SCt), Quality of Content (QC), Design (DG) and Development (DP) [7].

Table 1: List of Government Departments in Kerala considered for the study

\begin{tabular}{|l|l|}
\hline \multicolumn{1}{|c|}{ Departments } & \multicolumn{1}{c|}{ Website } \\
\hline State Election Commission Department & www.sec.kerala.gov.in [14 ] \\
\hline Dairy development Department & www.dairy.kerala.gov.in [15 ] \\
\hline Agriculture Department & www.keralaagriculture.gov.in [16 ] \\
\hline Backward Communities Development Department & www.bcdd.kerala.gov.in [17 ] \\
\hline tourism Department & www.keralatourism.gov.in [18 ] \\
\hline Collegiate Education Department & www.collegiateedu.kerala.gov.in [19 ] \\
\hline Scheduled Tribes Development Department & http://stdd.kerala.gov.in [20 ] \\
\hline General Education Department & www.education.kerala.gov.in [21] \\
\hline Labour and Rehabilitation Department & www.labour.kerala.gov.in [22 ] \\
\hline Public Works Department & www.keralapwd.gov.in [23 ] \\
\hline Revenue Department & revenue.kerala.gov.in [24 ] \\
\hline Genera Administration Special (A\&C ) Department & www.gadsplais.kerala.gov.in [25 ] \\
\hline Directorate of Industries and Commerce Training & www.dic.kerala.gov.in [26 ] \\
\hline Environment \& Climate change & www.envt.kerala.gov.in [27 ] \\
\hline IT Mission department of information Department Technology & www.itmission.kerala.gov.in [28 ] \\
\hline Sports \& youth Affair Department & www.dsya.kerala.gov.in [29 ] \\
\hline Directorate of Health Service Department & dhs.kerala.gov.in [30 ] \\
\hline Forest and wild life Department & www.forest.kerala.gov.in [31 ] \\
\hline Directorate of culture Department & www.culturedirectorate.kerala.gov.in [32 ] \\
\hline Department of Civil Supplies Department & www.civilsupplieskerala.gov.in [33 ] \\
\hline
\end{tabular}

Table 2: Groups and Parameters considered for the study

\begin{tabular}{|l|c|c|l|}
\hline \multicolumn{1}{|c|}{ Guidelines Groups } & $\begin{array}{c}\text { Actual } \\
\text { parameters }\end{array}$ & $\begin{array}{c}\text { Consider } \\
\text { Parameters }\end{array}$ & \multicolumn{1}{|c|}{ Parameters/Guidelines } \\
\hline $\begin{array}{l}\text { Government of India Identifier } \\
\text { (GII) }\end{array}$ & 5 & 4 & Emblem, title of the home page, registered under 'gov.in' or 'nic.in'. \\
\hline Building Confidence (BC) & 11 & 7 & $\begin{array}{l}\text { Copyright Policy, Hyper linking Policy, Terms \& Conditions, Privacy } \\
\text { Policy. }\end{array}$ \\
\hline Primary Content (SCp) & 21 & 19 & $\begin{array}{l}\text { About Us, Schemes, Services, Forms, Acts, Documents, } \\
\text { Circulars/notification, Tenders and Recruitment, News and Press } \\
\text { releases, Contact Us. }\end{array}$ \\
\hline Secondary Content (SCs) & 3 & 3 & $\begin{array}{l}\text { Outdated announcement removed to archive, Discussion Forums, } \\
\text { Complete URL of home page. }\end{array}$ \\
\hline Tertiary Content (SCt) & 7 & 5 & $\begin{array}{l}\text { Feedback, Help section, audio/video, free from discriminatory } \\
\text { language. }\end{array}$ \\
\hline Quality of Content (QC) & 14 & 0 & $\begin{array}{l}\text { Time stamp, free from spelling and Grammatical error, Consistency in } \\
\text { Nomenclature, Content review policy, Content contribution, } \\
\text { Moderation and Approval policy, Content Archival policy }\end{array}$ \\
\hline Design (DG) & 22 & 15 & $\begin{array}{l}\text { Emblem in proper ratio and color, resizing text without assistive } \\
\text { technology, A4 size paper, text for non-text element, textual } \\
\text { description for audio/video clips, mechanism to control scrolling and } \\
\text { blinking content, all page link to the home page, search page, Site } \\
\text { map. }\end{array}$ \\
\hline Development (DP) & & 18 & $\begin{array}{l}\text { Cascading style sheet, input error are flashed in text, content operable } \\
\text { through Keyboard, website tested on multiple browsers. }\end{array}$ \\
\hline
\end{tabular}

The Government of India Identifier (GII) are the following: The Government of India dictates all websites and portals belonging to the Indian Government domain at any hierarchical level (Apex Offices, Constitutional Bodies, Ministries, Departments, Organizations, States/UTs, District Administrations, and Village Panchayats) must prominently display a strong Indian identity and ownership of Indian
Government. Both public and private organizations should display their official emblem on the homepage of the website to highlight their identity. All important entry pages of the website must display the ownership information, either in the header or footer. The page title of the homepage must be complete with the name of the country or state. The title help for search engine and also visually weakened users in case the 
title is not explanatory enough, it may confuse or mislead. Building Confidence (BC): Content Copyright is a form of protection provided under law to the owners of "original works of authorship". An Indian Government website must have its hyperlinking policy defined and spelt out for those who wish to hyperlink content from any of its sections clearly defining Terms \& Conditions because of increase in access of information from Government websites. Scope of Content: Primary Content (SCp) shall be the original content that will be hunted by audiences of the website which could be citizens, the business community, or other Government departments. Examples of Primary Content are: information about the department, schemes and programmes, documents, forms etc. Secondary Content (SCs) are advertisements/banners/ spotlight / media gallery/related sites etc. Tertiary Content (SCt) about the Site, Online Help, Terms and Conditions and Frequently Asked Questions (FAQ). Quality of content (QC): The element of a Government content is written, presented and packaged on the web. Content should be written in simple language. Content on the website should be always authentic, up-to-date and latest. Home page and entry page of all Indian Government websites/portals should display a time stamp. The language used in a Government website must be free from any spelling or grammatical errors. Consistency, uniformity and regularity must be maintained across a website. Design (DG): Design is a process of presenting the content in a form that is easily understandable, navigation and search friendly for the user. Information on the website should be free from barriers of language. Text must be resizable without assistive technology and without loss of content. Images should be created in an appropriate format. There are three formats for displaying images in web browsers -GIF, JPEG and PNG. Development (DP): for the development of websites open standard based tools and software technologies are very important for interoperability, accessibility and user friendliness of websites. World Wide Web consortium (W3C) is a standard in web technology and formats, for publishing content on the web. HTML (Hypertext Markup Language) is at the core of the World Wide Web. Cascading Style Sheets (CSS) is a style sheet language used to describe the presentation of a document written in a markup language. Indian Government websites must use Cascading Style Sheets as much as possible to control layouts/styles [7].

The survey was conducted between January 2015 and December 2015. Kerala Government websites manually checking for compliances for a guideline. A website was visited several times to look for information and evaluation. For each metrics of a guideline a score between 0 and 1 was assigned. All the departments scored 1 and 0.5 values for each QC parameters. Mean and standard deviation of QC is same. Therefore Quality of content metrics is not considered to give rank for each departments. For 18 parameters all the departments were assigned zero values. These parameters are discarded from the calculations. A total score was calculated for 71 parameters. To give equal weightage to all the groups, the total score is normalized to 7 in each group.

\section{METHOD}

Let $\mathrm{w}_{\mathrm{gi}}^{\mathrm{x}}$ be the weightage assigned to a Departments $\mathrm{x}$, for a ith metrics of a guideline $g$. Let $W_{g}^{x}$ be the total weightage assigned to the department $\mathrm{x}$, for all the metrics of $\mathrm{a}$ guidelines $\mathrm{g}$. The following can be defined:

Weightage for GII guideline as

$\mathrm{W}_{\mathrm{GII}}^{\mathrm{x}}=\sum_{\mathrm{i}=1}^{4} \mathrm{w}_{\mathrm{GII}}^{\mathrm{x}}$
Weightage for $\mathrm{BC}$ guideline as

$\mathrm{W}_{\mathrm{BC}}^{\mathrm{x}}=\sum_{\mathrm{i}=1}^{7} \mathrm{~W}_{\mathrm{BCi}}^{\mathrm{X}}$

Weightage for $\mathrm{SCp}$ guideline as

$\mathrm{W}_{\mathrm{SCp}}^{\mathrm{X}}=\sum_{\mathrm{i}=1}^{19} \mathrm{w}_{\mathrm{SCp}}^{\mathrm{X}}$

Weightage for SCs guideline as

$\mathrm{W}_{\mathrm{SCs}}^{\mathrm{X}}=\sum_{\mathrm{i}=1}^{3} \mathrm{w}_{\mathrm{SC} S \mathrm{i}}^{\mathrm{X}}$

Weightage for SCt guideline as

$\mathrm{W}_{\mathrm{SCt}}^{\mathrm{x}}=\sum_{\mathrm{i}=1}^{5} \mathrm{~W}_{\mathrm{SCti}}^{\mathrm{x}}$

Weightage for DG guideline as

$\mathrm{W}_{\mathrm{DG}}^{\mathrm{X}}=\sum_{\mathrm{i}=1}^{15} \mathrm{~W}_{\text {DGi }}^{\mathrm{X}}$

Weightage for DP guideline as

$\mathrm{W}_{\mathrm{DP}}^{\mathrm{X}}=\sum_{\mathrm{i}=1}^{18} \mathrm{~W}_{\mathrm{DPi}}^{\mathrm{X}}$

The scores are assigned to the above mentioned guideline groups are between 0 and 1 . Four metrics are considered from GII, 7 metrics from BC, 19 metrics from SCp, and 3 metrics from SCs, 5 metrics from SCt, 15 metrics from DG, and 18 metrics from DP. For comparison of departments from various guidelines, the total score is normalized to 7 . Assuming that $\mathrm{k}$ is the number of metrics used in a guideline $\mathrm{g}$, for a department, $\mathrm{x}$. The normalized score $\mathrm{W}^{\prime} \underset{\mathrm{g}}{\mathrm{x}}$ is computed as follows:

$\mathrm{W}_{\mathrm{g}}^{\mathrm{x}}=\frac{7}{\mathrm{k}} * \mathrm{~W}_{\mathrm{g}}^{\mathrm{x}}$

Let $\mu_{g}$ be the mean weightage of all departments for a guideline $\mathrm{g}$. We define mean for GII, BC, SCp, SCs, SCt, DG and $\mathrm{DP}$ as $\mu_{\mathrm{GII}}, \mu_{\mathrm{BC}}, \mu_{\mathrm{SCp}}, \mu_{\mathrm{SCs}}, \mu_{\mathrm{SCt}}, \mu_{\mathrm{DG}}$, and $\mu_{\mathrm{DP}}$ respectively. Let $\sigma_{\mathrm{GII}}, \sigma_{\mathrm{BC}}, \sigma_{\mathrm{SCp}}, \sigma_{\mathrm{SCs}}, \sigma_{\mathrm{SCt}}, \sigma_{\mathrm{DG}}$ and $\sigma_{\mathrm{DP}}$ be standard deviation (SD) of GII, BC, SCp, SCs, SCt, , DG and DP respectively. Table 3 shows the mean and standard deviation (SD) of all the metrics. Grade $r_{g}$ for a guideline $g$ where $\subset\{$ GII, BC, SCp, SCs, SCt, QC, DG, DP $\}$ for a department $\mathrm{x}$ can be defined as follows:

$r_{g}=\left\{\begin{array}{c}\operatorname{Average}(\mathrm{A}) \text { if }\left(\mu_{\mathrm{g}}-\sigma_{\mathrm{g}}\right) \leq \mathrm{W}_{\mathrm{g}}^{\prime} \leq\left(\mu_{\mathrm{g}}+\sigma_{\mathrm{g}}\right) \\ \text { Good (G) if } \mathrm{W}_{\mathrm{g}}^{\prime}>\mu_{\mathrm{g}}+\sigma_{\mathrm{g}} \\ \text { Poor (P) if } \mathrm{W}_{\mathrm{g}}^{\prime}<\mu_{\mathrm{g}}-\sigma_{\mathrm{g}}\end{array}\right.$

Table 3: Mean and Standard deviation (SD) of each Groups

\begin{tabular}{|c|l|l|l|l|l|l|l|}
\hline \multirow{2}{*}{$\begin{array}{l}\text { Mean } \\
\text { \& SD }\end{array}$} & \multicolumn{7}{|c|}{ Groups } \\
\cline { 2 - 8 } & GII & BC & SCp & SCs & SCt & DG & DP \\
\hline Mean & 3.05 & 2.8 & 9.6 & 0.625 & 3.5 & 10.725 & 16.725 \\
\hline SD & 0.49 & 1.12 & 4.01 & 0.68 & 0.85 & 0.99 & 0.53 \\
\hline
\end{tabular}

\section{ANALYSIS}

For GII guidelines, Schedule tribe department and Tourism department websites scored the lowest weight points and were awarded grade: average. The rest of the department websites scored the highest weight points and awarded grade: good. None of the departments graded poor.

For BC guidelines, department of Civil Supplies and General Education department websites have scored the highest 
weight points for all the Building Confidence parameters and was graded: good. Rest of the departments scored the lowest weight points and were graded: average. None of the departments graded poor.

For Primary Content guidelines, Collegiate Education department, and General Education department websites scored the highest weight points and were graded average. Rest of the departments obtained grade poor. None of the departments were awarded with the grade: good. State Election Commission department, Directorate of culture department, Scheduled Tribes Development department, Labour and Rehabilitation department, Sports \& youth Affairs department, and Directorate of Health Service department websites have scored very less weight points. Revenue Department, and General Administration special department's websites had not bothered to follow Primary Content guidelines and were scored less weight points.

For Secondary Content guidelines, some of the departments were assigned score zero weight points and have not follow the metrics of the Secondary Contents guidelines and were awarded grade: poor. The rest of the departments were graded good and average.

For Tertiary Content guidelines the Directorate of culture department, Tourism department, Scheduled Tribes Development department, General Education department, Labour and Rehabilitation department, Public Works department, Environment \& Climate change department, Sports \& youth Affairs department, Directorate of Health Service department, and Forest and wild life department websites obtained grade: average. The Revenue department, and General Administration special department websites obtained grade poor with less weight points. The rest of the department websites obtained grade good.

For Design and Development guidelines, all the departments obtained grade poor. None of the departments websites were awarded neither good nor average grades.

Total weightage assigned to a department $\mathrm{x}$, as $\mathrm{WT}^{\mathrm{x}}$ for guidelines $\mathrm{g}$ from 1 to 7 is defined as follows:

$\mathrm{WT}^{\mathrm{x}}=\sum_{\mathrm{g}=1}^{7} \mathrm{WT}_{\mathrm{g}}^{\mathrm{x}}$

Table 4 shows the total weightage and the relative rank of the departments. The department with the maximum WT score is assigned the first rank and department with the minimum WT score is assigned the rank 20. Department of Civil Supplies website is at the top of list and the Revenue department website is at the bottom of the table.

\section{CONCLUSION}

Twenty Government departments websites located in the portal of the state of Kerala have been evaluated. Guidelines considered for survey are grouped as Government of India Identifier (GII), Building Confidence (BC), Primary Content (SCp), Secondary Content (SCs) and Tertiary Content (SCt), Quality of Content (QC), Design (DG), and Development (DP). The evaluation was based on 71 metrics. Ranks were assigned to websites on the performance of individual departments and groups. Grades: Good (G), Average (F), and Poor $(\mathrm{P})$ grades were assigned to each department. It was found that the department of Civil Supplies website performed better than the others. The Revenue Department website is ranked the last. Department of Civil Supplies website total weight point is WT $=36.41$ and ranked first. Many Government departments websites have not followed Building Confidence guidelines, such as copyright policy, hyperlinking policy and no indication when their link leads to nonGovernment websites, terms \& conditions, privacy policy. For all these metrics, many departments were assigned score 0 value. State Election Commission department, Labour and Rehabilitation department, Revenue department, General Administration Special departments and Tourism department websites have not followed Primary Content guidelines and assigned score 0 and some websites have maximum value 15.5. Except Directorate of Health Service department and State Election commission department websites, all other department websites have not followed the secondary content guidelines and were assigned score 0 . In Most of the department websites, the site map is not linked to the home page, there was no search box in the home page and in every subsequent entry pages of the websites. The following recommendations are made to improve department websites.1. The websites can be designed for the use of education, culture, employment, business, government, health, personal and public, 2. A department website must be designed for local public consumption in the local language, 3. In many departments websites, old notification, tender, notices and outdated announcements are not moved into the archive section, 4. In most of the department websites, there is no mechanism to handle broken links, 5. For non-text elements, alternative text is not provided and there should be a mechanism to control blinking and scrolling of content making it very difficult to go through the web pages by visually challenged people.

Table 4: Ranking of each department

\begin{tabular}{|l|l|l|l|l|l|l|l|l|l|}
\hline \multicolumn{1}{|c|}{ Department Names } & $\mathbf{W}_{\mathbf{G I I}}^{\prime \mathbf{x}}$ & $\mathbf{W}_{\mathbf{B C}}^{\prime \mathbf{X}}$ & $\mathbf{W}_{\mathbf{S C p}}^{\prime \mathbf{X}}$ & $\mathbf{W}_{\mathbf{S C s}}^{\prime \mathbf{x}}$ & $\mathbf{W}_{\mathbf{S C t}}^{\prime \mathbf{X}}$ & $\mathbf{W}_{\mathbf{D G}}^{\prime \mathbf{x}}$ & $\mathbf{W}_{\mathbf{D P}}^{\prime \mathbf{X}}$ & \multicolumn{1}{|c|}{$\mathbf{W T}$} & $\mathbf{R A N K}$ \\
\hline Department of Civil Supplies & 7 & 7 & 5.3 & 0 & 5.6 & 4.9 & 6.61 & 36.41 & 1 \\
\hline State Election commission Department & 7 & 2.5 & 2.94 & 5.83 & 5.6 & 4.9 & 6.61 & 35.38 & 2 \\
\hline Agriculture department & 5.25 & 2.5 & 5.15 & 2.33 & 7 & 5.6 & 6.61 & 34.44 & 3 \\
\hline Dairy development Department & 5.25 & 2.5 & 4.78 & 1.16 & 7 & 5.13 & 6.61 & 32.43 & 4 \\
\hline $\begin{array}{l}\text { IT Mission department of information } \\
\text { Technology }\end{array}$ & 5.25 & 2 & 4.05 & 2.33 & 6.3 & 5.6 & 6.8 & 32.33 & 5 \\
\hline General Education Department & 5.25 & 5 & 5.71 & 0 & 4.2 & 4.9 & 6.22 & 31.28 & 6 \\
\hline Forest and wild life Department & 5.25 & 2.5 & 4.78 & 2.33 & 4.2 & 5.13 & 6.22 & 30.41 & 7 \\
\hline Collegiate Education Department & 5.25 & 2.5 & 5.71 & 0 & 5.6 & 4.9 & 6.22 & 30.18 & 8 \\
\hline $\begin{array}{l}\text { Directorate of Industries and Commerce } \\
\text { Training Department }\end{array}$ & 5.25 & 2.5 & 3.68 & 0 & 6.3 & 5.36 & 6.8 & 29.89 & 9 \\
\hline $\begin{array}{l}\text { Backward Communities Development } \\
\text { Department }\end{array}$ & 5.25 & 2.5 & 3.68 & 1.16 & 5.6 & 4.9 & 6.61 & 29.7 & 10 \\
\hline Environment \& Climate change Department & 5.25 & 2.5 & 3.68 & 2.33 & 4.9 & 4.43 & 6.41 & 29.5 & 11 \\
\hline
\end{tabular}




\begin{tabular}{|l|l|l|l|l|l|l|l|l|l|}
\hline Directorate of Health Service Department & 5.25 & 2.5 & 3.31 & 1.89 & 4.2 & 5.6 & 6.41 & 29.16 & 12 \\
\hline Labour and Rehabilitation Department & 7 & 2.5 & 1.84 & 1.16 & 4.9 & 4.9 & 6.8 & 29.1 & 13 \\
\hline Public Works Department & 5.25 & 2.5 & 3.68 & 0 & 4.9 & 5.6 & 6.8 & 28.73 & 14 \\
\hline Directorate of culture Department & 5.25 & 2.5 & 3.31 & 1.16 & 4.2 & 5.36 & 6.22 & 28 & 15 \\
\hline Sports \& youth Affairs Department & 5.25 & 2.5 & 1.84 & 2.33 & 4.2 & 5.36 & 6.41 & 27.89 & 16 \\
\hline Tourism Department & 3.5 & 2.5 & 3.68 & 2.33 & 4.2 & 4.2 & 6.61 & 27.02 & 17 \\
\hline General Administration special departments & 5.25 & 2.5 & 0.92 & 0 & 2.8 & 4.9 & 6.41 & 22.78 & 18 \\
\hline Scheduled Tribes Development Department & 3.5 & 2.5 & 2.21 & 0 & 3.5 & 4.43 & 6.22 & 22.36 & 19 \\
\hline Revenue Department & 5.25 & 2.5 & 0.36 & 0 & 2.8 & 3.96 & 6.41 & 21.28 & 20 \\
\hline
\end{tabular}

\section{REFERENCES}

[1] Nikita Yadav and V.B.Singh (2012). E Governance: Past, present, Future in India. International Journal of Computer Applications (0975-8887), Volume 53-No. 7.

[2] Vandana Gupta and Ajay Sharma. E Governance in India: Problems, Challenges and Prospects. The International Journal research Publication's (TIJRP), TIJ's research journal of Economics and Business Studies ISSN 2251-1555.

[3] Prajakta N.Warale and Hemalatha Diwakar (2015). A Study of Citizen Satisfaction for e-Governance Initiative SETU in Maharashtra (INDIA). International journal of computer applications (0975-8887). Volume 124-No. 17.

[4] Dr. R.Siva Rama Prasad and Veera RaghavaRao Atukuri (2012). Cloud Computing Technology for Effective eGovernance. IJCSIT (ISSN-0975-9646), Vol. 3 (1), 3241-3244.

[5] Muralidhara B L and Amthul Hai (2013). A comparative study of Universities in Karnataka. International journal of computer applications (0975-8887). Volume 65.

[6] Census organization of India. Viewed on 14th January, 2016 from www.census2011.co.in

[7] Government of India. Guidelines for Indian Government websites. Downloaded on 4th December 2015 from http://darpg.nic.in

[8] http://www.guidelines.gov.in . Viewed on 10th January, 2015

[9] Census of India 2011. Viewed on 14th January, 2016 from censusindia.gov.in.

[10] http://www.indiaonlinepages.com. Viewed on 14th January, 2016.

[11] The official Web Portal Government of Kerala. Viewed on 5th December, 2015 from www.kerala.gov.in

[12] National Portal of India. Viewed on 5th December, 2015 from india.gov.in

[13] http://www.stateofkerala.in viewed on 14th January 2016.

[14] State Election commission Department. Viewed on 6th December, 2015 from http://www.sec.kerala.gov.in.

[15] Dairy development Department. Viewed on 7th December, 2015 from http://www.dairy.kerala.gov.in.

[16] Agriculture Department. Viewed on 8th December, 2015 from http://www.keralaagriculture.gov.in.

[17] Backward Communities Development Department. Viewed on 9th December, 2015 from http://www.bcdd.kerala.gov.in.
[18] Tourism Department. Viewed on 10th December, 2015 from http;//www.keralatourism.gov.in.

[19] Collegiate Education Department. Viewed on 10th December, 2015 from www.collegiateedu.kerala.gov.in.

[20] Scheduled Tribes Development Department viewed on 12th December, 2015 from http://stdd.kerala.gov.in.

[21] General Education department viewed on 12th December, 2015 from http://www.education.kerala.gov.in.

[22] Labour and Rehabilitation Department viewed on 15th December, 2015 from http://www.labour.kerala.gov.in.

[23] Public Works Department. Viewed on 16th December, 2015 from http://www.keralapwd.gov.in.

[24] Revenue Department. Viewed on 16th December, 2015 from http://revenue.kerala.gov.in.

[25] General Administration Special (A\&C) Department. Viewed on 18th December, 2015 from www.gadsplais.kerala.gov.in.

[26] Directorate of Industries and Commerce Training Department. Viewed on 19th December 2015 from www.dic.kerala.gov.in

[27] Environment \& Climate change Department. Viewed on 19 December, 2015 from http://www.envt.kerala.gov.in.

[28] IT Mission department of information Technology Department. Viewed on 20th December 2015 from [http://www.itmission.kerala.gov.in.

[29] Sports \& youth Affairs. Viewed on 20th December 2015 from http://www.dsya.kerala.gov.in.

[30] Directorate of Health Service Department. Viewed on 21st December, 2015 from http://dhs.kerala.gov.in.

[31] Forest and wild life Department. Viewed on 21st December, 2015 from http://www.forest.kerala.gov.in.

[32] Directorate culture Departments. Viewed on 22nd December,2015fromhttp://www.culturedirectorate.kerala .gov.in.

[33] Department of Civil Supplies. Viewed on 23rd December,2015fromhttp://www.civilsupplieskerala.gov.i n. 